\title{
Shuffling the cards won't change your hand: Reclassifying congenital heart surgery cases by complexity
}

\author{
Tara Karamlou, MD, MSc, ${ }^{\mathrm{a}}$ and Anusha Jegatheeswaran, $\mathrm{MD}, \mathrm{PhD}^{\mathrm{b}}$
}

\footnotetext{
From the a Division of Cardiovascular Surgery, Department of Surgery, University of California, San Diego, and Division of Cardiac Surgery, Rady Children's Hospital, San Diego, Calif; and bivision of Cardiovascular Surgery, Department of Surgery, University of Toronto, and Hospital for Sick Children, Toronto, Ontario, Canada. Disclosures: Authors have nothing to disclose with regard to commercial support.

Received for publication June 28, 2018; accepted for publication June 29, 2018; available ahead of print Aug 11, 2018.

Address for reprints: Tara Karamlou, MD, MSc, Division of Cardiac Surgery, Rady Children's Hospital, 3020 Children's Way, San Diego, CA (E-mail: tarakaramlou@gmail.com).

J Thorac Cardiovasc Surg 2018;156:1968-9

$0022-5223 / \$ 36.00$

Copyright (C) 2018 by The American Association for Thoracic Surgery

https://doi.org/10.1016/j.jtcvs.2018.06.086
}

Gupta and colleagues ${ }^{1}$ investigated whether reclassification of patients according to the highest complexity operation during an admission rather than the first, or index, operation (as is currently done by The Society of Thoracic SurgeonsEuropean Association of Cardio-Thoracic Surgery Congenital Heart Surgery [STAT] mortality classification system) would change the "risk-adjusted reporting landscape" in congenital heart surgery. They looked at 22,393 patients aged $<18$ years undergoing reoperations during the same admission during a 6-year period in the Virtual Pediatric Systems Database. The authors found that the number of patients in the lowest STAT complexity category (STAT 1) was 2.5 times higher using the index classification system compared to the authors' proposed system. Furthermore, in the authors' system, there was a drop in the number of STAT 1 patients and an increase in the number of patients in the higher STAT categories. Mortality was higher across all of the STAT categories when patients were classified by the index operation. The authors hypothesized that the current system, which uses the index operation, may falsely inflate mortality due to misclassification of patients into lower risk categories.

The recategorization of patients undergoing more than 1 operation during the same admission will predictably shift patients into higher complexity categories, and therefore bias the results toward higher STAT categories. However, this subset of patients also provides an opportunity to further investigate those who undergo reoperations intentionally (eg, a staged approach for newborn infants undergoing bilateral pulmonary artery banding followed by a rapid-stage Norwood operation), compared with those patients who undergo unplanned reoperations (eg, residual lesions requiring intervention). Clearly, improving the discrimination of current risk-adjustment models (the authors found that the $c$-statistic increased from 0.77 with the current classification algorithm to 0.89 with their algorithm) would be extremely helpful to understand these comparison. comparison.

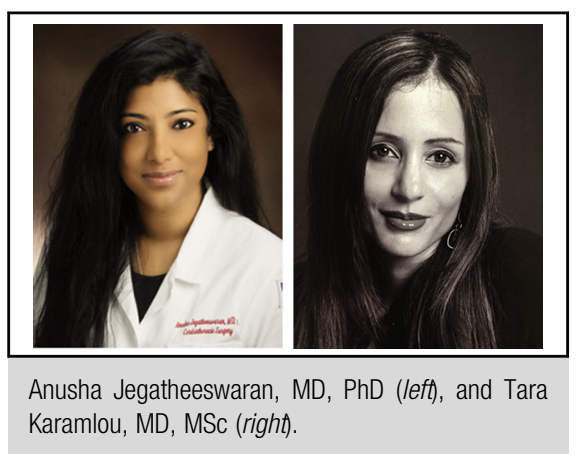

Central Message
Reclassifying patients using highest
complexity operation, rather than index opera-
tion of an admission, may shift them predict-
ably into different categories; however, it
won't change the landscape.

See Article page 1961.

discrepant groups. This was among the most provocative and interesting components of the analysis. The system proposed by the authors could also provide mechanisms for managing expectations for these higher-risk populations and for improving perioperative care pathways. Given that the present study ostensibly aims to improve the fidelity of the currently employed index operation classification system, it would have been useful to compare the results of patients undergoing unplanned versus planned reoperations using both systems because this would be a critical

The use of the Virtual Pediatric Systems dataset further confuses matters, and we believe that the study would be clearer had the authors chosen to use The Society of Thoracic Surgeons (STS) Congenital Heart Surgery Database (the dataset from which the STAT mortality risk-model is derived) to execute their study. Although the authors are not reproducing risk models developed by the STS Database Taskforce, they are comparing the current STS classification system with their own system. ${ }^{2,3}$ As such, using this dataset would have allowed for a better head-to-head

Let's face it: We need another classification system for congenital heart disease about as badly as a fish needs a bicycle. ${ }^{4}$ The value of the study by Gupta and colleagues lies in the promise of providing a mechanism to increase 
the discrimination of risk stratification to predict outcomes. A more accurate risk-stratification system would potentially lead to increased participation because centers may feel less threatened to report their results. Despite this, the authors described predictable changes in grouping and outcomes using their reclassification system (albeit in a high-complexity, skewed population), but they did not evaluate whether this system changes the landscape of reporting for congenital heart surgery. Meaningful changes in reporting will be predicated on changes in patterns of participation (which is itself constrained by resources within each center), minimization of data errors, and a commitment to quality and process improvement. Current initiatives within the STS Database Taskforce are focused on investigating diagnosis-based rather than procedurebased classification, improving calibration, and weighting of variables to account for the relative influence of factors such as timing of adverse events. We applaud Gupta and colleagues for their thoughtful approach to the important problem of assessing the current imperfect system, but we are not convinced that anyone has found the best path forward.

\section{References}

1. Gupta P, Rettiganti M, Shinkawa T, Gossett JM, Brundage N, Jeffries HE Bertrandt RA. Reclassifying by highest complexity operation rather than first operation influences mortality after pediatric heart surgery. J Thorac Cardiovasc Surg. 2018;156:1961-7.

2. O'Brien SM, Jacobs JP, Pasquali SK, Gaynor JW, Karamiou T, Welke KF, et al The Society of Thoracic Surgeons congenital heart surgery database mortality risk model: part 1-statistical methodology. Ann Thorac Surg. 2015;100:1054-62.

3. Jacobs JP, O’Brien SM, Pasquali SK, Gaynor JW, Mayer JE Jr, Karamlou T, et al The Society of Thoracic Surgeons congenital heart surgery database mortality risk model: part 2-clinical application. Ann Thorac Surg. 2015;100:1063-8; discussion 1068-70.

4. Allen JS. "A bit of herstory: the definitive word on the origin!" Available at: http:// john-s-allen.com/humor/herstory.htm. Accessed July 1, 2018. 